\title{
Experimental study on spraying performance of biological pesticides in aerial rotary cage nozzle
}

\author{
Yu Ru ${ }^{1 *}$, Yangyang Liu ${ }^{1}$, Rongjia Qu ${ }^{1}$, Manoj Kumar Patel ${ }^{2,3}$ \\ (1. Collage of Mechanical and Electrical Engineering, Nanjing Forestry University, Nanjing 210037, China; \\ 2. CSIR-Central Scientific Instruments Organisation, Chandigarh 160030, India; \\ 3. Academy of Scientific and Innovative Research, AcSIR-CSIO, Chandigarh 160030, India)
}

\begin{abstract}
Aviation spraying is one of the most important methods for the treatment of forestry pests and diseases, which has a high operation efficiency and effectiveness. The combination of aviation spray and biological pesticides to reduce the impact of pesticide spray on environment has become an important development in the direction of agricultural aviation. In order to explore the effects of aviation spray parameters on particle size distribution and activity retention of biological pesticide droplets, a system of droplets size test and an activity retention rate test system of biological pesticides were constructed. The related experiments were conducted by changing the structural parameters of the rotary cage nozzle (the diameter of nozzle) and the technical parameters of the operation (rotary speed and flow rate). The results showed that the average relative width $S$ of the droplets of the rotary cage nozzle was close to 1 , and the droplet distribution was uniform. The influence factors on the particle size distribution of biological pesticide droplets were rotary speed, nozzle diameter, medium and flow rate in descending order. The rotary speed, nozzle diameter, and medium had a significant influence on droplet size distribution. The average activity retention rate of Bacillus thuringiensis was $88.83 \%$, and the germination rate of Beauveria bassiana was $89.80 \%$. The rotary speed had a significant effect on the activity retention rate of bacterial and fungal biological pesticides, and it was negatively correlated. The rotary speed was between 3000-5000 r/min, and the activity retention rate was higher. The research results can provide guidance for spraying biological pesticides in aerial plant protection operations with rotary cage nozzle.
\end{abstract}

Keywords: forestry disease and pest control, biological pesticide, activity retention rate, aerial rotary cage nozzle, droplet distribution

DOI: $10.25165 /$ j.ijabe.20201306.5511

Citation: Ru Y, Liu Y Y, Qu R J, Patel M K. Experimental study on spraying performance of biological pesticides in aerial rotary cage nozzle. Int J Agric \& Biol Eng, 2020; 13(6): 1-6.

\section{Introduction}

China has a serious occurrence of forestry diseases and pests, with an average annual area of more than 178 million $\mathrm{mu}^{[1]}$. Aviation plant protection has the advantages of high operational efficiency, strong assault ability, better control effect, and no restriction on crop growth. It is an important way to solve the problem of sudden and large-scale agro-forestry diseases and pests $^{[2-4]}$.

At present, China is actively advocating the field of $R \& D$ (Research and Development), as well as the application of the "comprehensive technology for chemical fertilizers and pesticide reduction and improvement" ${ }^{,[5]}$. Aviation spray of biological pesticide is an effective method with the advantages of reduced pollution and residues on commodities ${ }^{[6-9]}$. Furthermore, the prevention and control of agricultural and forestry diseases and pests are important research field. The uniformity of droplet distribution and the activity retention rate are important factors

\section{Received date: 2019-11-08 Accepted date: 2020-05-10}

Biographies: Yangyang Liu, $\mathrm{PhD}$, research interests: aviation plant protection, Email: 646991591@qq.com; Rongjia Qu, Master, research interests: plant protection, Email: 1392384662@qq.com; Manoj Kumar Patel, Senior Scientist, research interests: plant protection, Email: manoj_patel@csio.res.in.

*Corresponding author: Yu Ru, Professor, Doctoral Supervisor, research interests: plant protection. Collage of Mechanical and Electrical Engineering, Nanjing Forestry University, Nanjing 210037, China. Tel: +86-13951778251, Email: superchry@163.com. impacting the control effect of biological pesticide after the spray ${ }^{[10,11]}$. Doruchowski et al. ${ }^{[11]}$ used different types of nozzles to carry out the distribution test and activity experiments of nematodes, and the results showed that the type of nozzle and the pressure of spraying had a significant effect on the activity of biological pesticides. Hidalgo et al. ${ }^{[12]}$ used a conical nozzle to spray a fungal biological pesticide, and the results showed that different kinds of bio-pesticides have significant differences in the control effect of Candida. Molina-Miras et al. ${ }^{[13]}$ found that shear stress is a key variable affecting the sensitivity of biological cells in fluid. Gouli et al. ${ }^{[14]}$ used different types of nozzles to spray fungal biological pesticides. It was confirmed that the spray pressure and flow rate had a significant impact on the activity of total spore activity of biological pesticides, and the lower the flow rate at the outlet, the smaller the damage to the activity of biological pesticides. Fife et al. ${ }^{[15]}$ used conical nozzles and planar sector nozzles to carry out the effects of pressure difference and flow rate on nematode activity. The experimental results showed that the nematode activity through conical nozzles was stronger than via planar sector nozzles, and the differential pressure threshold was $1.283 \mathrm{MPa}$, when the pressure exceeds the threshold, the nematode activity will rapidly decrease ${ }^{[16-19]}$. Li et al. ${ }^{[20]}$ and Zhai et al. ${ }^{[21]}$ carried out numerical simulation and experimental verification on the process of spraying biological pesticides on hollow cone spray nozzles, where the results showed that the nozzle orifice size and spray pressure were negatively correlated with the bacteria activity. Zhang et al. ${ }^{[22-24]}$ studied the rotary 
cage atomization nozzles with ground-spraying mechanical biological pesticide and rotary disc atomizing nozzles, and tested their atomization performance and biological activity retention rate. At present, the research on biological pesticide spraying focuses on the nozzles used in ground spray machinery, including hydraulic nozzles, centrifugal turntable nozzles, and electric cage nozzles ${ }^{[25-27]}$. However, the structure and working mode of the nozzle used in the ground spray are different from those of the aerial nozzle. The effect of the structure of the rotary cage nozzle and the high speed produced by aircraft on the droplet spectrum and pesticide activity has not been studied. Therefore, the effects of the structural parameters and flight operation parameters of the rotary cage nozzle on the distribution uniformity and activity of the biological pesticide droplets under the condition of high speed airflow are studied by using the wind tunnel to simulate the flight speed of the aircraft. It is of great significance for the promotion of aero-spraying biological pesticides.

\section{Materials and methods}

\subsection{Test device and materials}

The test system consists of a high-speed wind tunnel system (variable-frequency controller, high-speed fan, high-speed wind tunnel), rotary cage nozzle, sampling device (collection station, Petri dish), liquid supply system (water tank, Piston pump, valve switch, pressure gauge, Flow valve, collection tank), laser particle size analyzer test system (laser particle size analyzer, computer) and tachometer, as shown in Figure 1. Here, a high-speed wind tunnel (IEA-1 type, Agricultural Intelligent Equipment Technology Research Center of Beijing Academy of Agriculture and Forestry, with adjustable wind speed of $0-98 \mathrm{~m} / \mathrm{s}$ ) is used to simulate the high-speed airflow generated by aircraft flight during aerial spray operations. There are three kinds of rotary cage nozzles (CYD-1, CYD-2, CYD-3) with diameters of $105 \mathrm{~mm}, 85 \mathrm{~mm}$, and $65 \mathrm{~mm}$, respectively, as shown in Figure 2. The upper and lower wheels are installed on the outside of the nozzle to install the blade. The blades come in two different lengths: $68 \mathrm{~mm}$ and $94 \mathrm{~mm}$. The upwind angle can be adjusted in the range of $0^{\circ}$ to $90^{\circ}$ when the blade is installed.

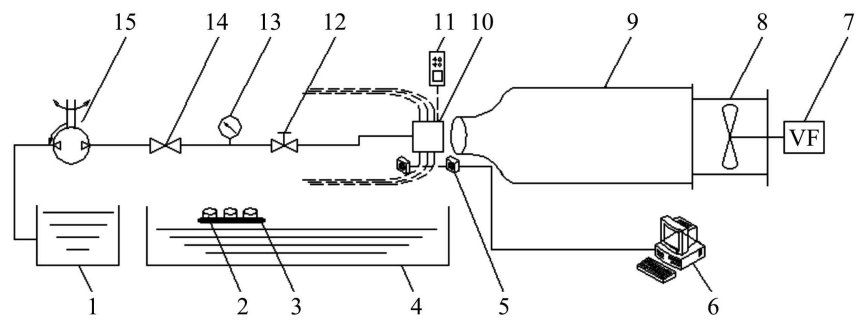

1. Water tank 2. Collection station 3. Petri dish 4. Collection tank

5. Laser particle size analyzer 6. Computer 7. Variable-frequency controller

8. High-speed fan 9. High-speed wind tunnel 10. Rotary cage nozzle

11. Tachometer 12. Flow valve 13. Pressure gauge 14. Valve switch

15. Piston pump

Figure 1 High speed wind tunnel spraying capabilities test system

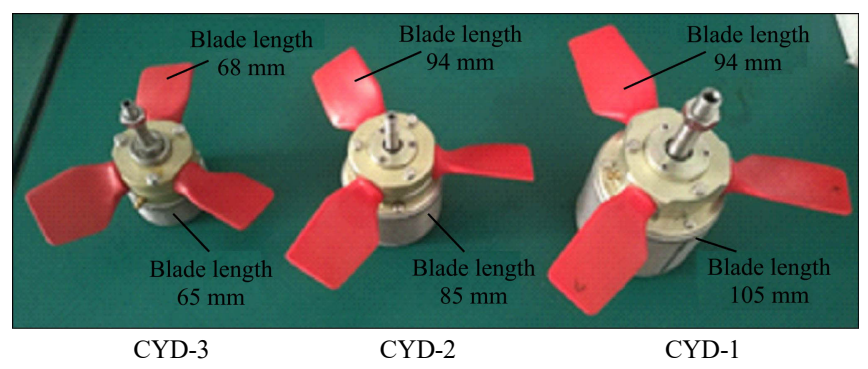

Figure 2 Three aerial rotary cage nozzles
The nozzle is fixed by the bracket at about $20 \mathrm{~cm}$ away from the wind tunnel, and is located at the center point of the wind tunnel exit. The sampling device (positioned $2 \mathrm{~m}$ downstream of the wind tunnel) is used to place the petri dish, and after the spray state is stable, the atomized biological pesticide is collected at the same time. The liquid supply system supplies the liquid in the water tank to the rotary cage nozzle. The flow rate can be adjusted by flow valve. The droplet spectrum of each point in the spray area generated by the rotary cage nozzle is measured by a mobile Malvern Laser Particle Size Analyzer (UK, measuring particle size range of $0.1-1000 \mu \mathrm{m}$, acquisition frequency up to 20 $\mathrm{kHz}$ ); the Laser Particle Size Analyzer is arranged at the exit of the relative wind tunnel at $0.5 \mathrm{~m}$ (as shown in Figure 3); and the activity retention rate is detected in the aseptic laboratory ${ }^{[28]}$.

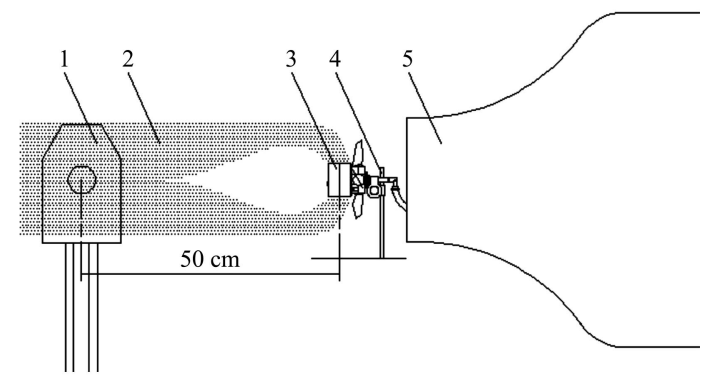

1. Laser particle size analyzer $\quad 2$. Spray area $\quad 3$. Rotary cage nozzle 4. Nozzle bracket 5. High-speed wind tunnel

Figure 3 The droplet spectrum test field

Bacterial or fungal biological pesticides are usually used for the treatment of agricultural and forestry diseases and pests. Among the pesticides used in the test, the bacterial bio-pesticides are $8000 \mathrm{IU} / \mathrm{mg}$ suspension of Bacillus thuringiensis, diluted at a ratio of 1:300; and the fungal biological pesticides are $2 \times 10^{5} \mathrm{CFU} / \mathrm{mg}$, where Beauveria bassiana powder was mixed with water at a ratio of $1: 100$ to form a suspension.

\subsection{Experiment method}

\subsubsection{Speed calibration}

In order to explore the influence of rotary speed of rotary cage nozzle on biological pesticide activity, it is necessary to calibrate the rotary speed of three kinds of rotary cage nozzles in advance to prepare the test parameters for droplet spectrum test and activity test. The rotary speed of the rotary cage nozzle was determined by the wind speed of the high-speed wind tunnel, the windward angle of the blade, and the length of the blade, where it could be calibrated by a tachometer. The purpose of this experiment is to obtain the parameter calibration tests of rotary cage nozzles with three different diameters in droplet size distribution test and biological pesticide activity determination experiment, $3000 \mathrm{r} / \mathrm{min}$, $5000 \mathrm{r} / \mathrm{min}$, and $7000 \mathrm{r} / \mathrm{min}$ speed calibration test; 2 blade lengths; 3 blade angles; and multiple wind speeds were selected in experiment. Taking into consideration that the actual working speed of the R44 aircraft is $90-160 \mathrm{~km} / \mathrm{h}$, that is, $25-44.5 \mathrm{~m} / \mathrm{s}$, the wind speed is debugged in this interval by the variable-frequency controller. The test factor levels are shown in Table 1. When the speed was measured, the reflective stickers for the tachometer was attached to the nozzle net cage, and the required speed of the diameter rotary cage nozzle could be obtained by adjusting the parameters set by different tests.

\subsubsection{Measurement of droplet size distribution}

The laser particle size analyzer directly measured the $\mathrm{D}_{\mathrm{V} 10}$, $\mathrm{D}_{\mathrm{V} 50}$, and $\mathrm{D}_{\mathrm{V} 90}$ of the droplets after the spraying of the rotary cage nozzle to evaluate the uniformity of the droplet size distribution. The spraying mediums were water, Bacillus thuringiensis, and 
Beauveria bassiana. The test object is three kinds of rotary cage nozzles with different diameters, three rotary speeds, and three kinds of flow rate. The test factor level is shown in Table 2, and the speed is selected by calibration test. According to the spray pressure of the actual aviation spray operation, the spray pressure was set to $0.25 \mathrm{MPa}^{[29]}$, and the flow rate can be adjusted through different gear positions of the flow valve. Before the test, the biological pesticide and water should be thoroughly mixed to ensure uniform concentration of the sprayed liquid. The room temperature was constant during the test, each group of experiments was repeated 3 times, and the outlier was removed and analyzed.

Table 1 Speed test parameters of the rotary nozzle

\begin{tabular}{|c|c|}
\hline Factor & Level \\
\hline Diameter of the nozzle/mm & $\begin{array}{lll}105 & 85 & 65\end{array}$ \\
\hline Wind speed $/ \mathrm{m} \cdot \mathrm{s}^{-1}$ & $25.5-44.6$ \\
\hline Blade length/mm & $94 \quad 68$ \\
\hline Blade angle $/\left({ }^{\circ}\right)$ & $\begin{array}{lll}25 & 35 & 45\end{array}$ \\
\hline
\end{tabular}

Table 2 Experimental parameters for the test

\begin{tabular}{lccc}
\multicolumn{1}{c}{ Factor } & \multicolumn{3}{c}{ Level } \\
\hline Rotary speed $/ \mathrm{r} \cdot \mathrm{min}^{-1}$ & 3000 & 5000 & 7000 \\
Diameter of the nozzle/mm & 105 & 85 & 65 \\
Flow rate $/ \mathrm{L} \cdot \mathrm{min}^{-1}$ & 4.4 & 10.5 & 11.1 \\
Medium & Water & $\begin{array}{c}\text { Bacillus } \\
\text { thuringiensis }\end{array}$ & $\begin{array}{c}\text { Beauveria } \\
\text { bassiana }\end{array}$
\end{tabular}

\subsubsection{Determination of biological pesticide activity}

The determination of biological pesticide activity is simultaneously performed using the distribution test of droplet size. Two biological pesticide preparations of $2 \times 10^{5} \mathrm{CFU} / \mathrm{mg}$ of Beauveria bassiana and $8000 \mathrm{IU} / \mathrm{mg}$ of Bacillus thuringiensis were used. When spraying, the spray pressure was set to $0.25 \mathrm{MPa}$, with the flow rate and speed selected being shown in Table 2. After spraying, the liquid was collected with the petri dish. The spray solution was set as the experimental group, and the solution that had not passed through the nozzle was set as the control group. The samples of the experimental group and the control group were sent to the aseptic laboratory and cultured in the MIR-554-pc constant temperature incubator of the Panasonic Company of Japan as the pre-treatment of the detection test of the activity retention rate.

When the activity retention rate of Bacillus thuringiensis was detected, the sample liquid was diluted by $10^{-1}, 10^{-2}$, and $10^{-3}$ gradients. The coating test was then carried out, and $100 \mu \mathrm{L}$ of the diluted drug solution was taken and uniformly coated with a glass spatula. On the solid nutrient base, each dilution of every sample was applied 3 times. After the application was evenly applied, the petri dish was sealed with a sealing film, and the sealed petri dish was placed in an incubator at $28^{\circ} \mathrm{C}$ for $16 \mathrm{~h}$. The germination of single colony was counted and performed. When the activity retention rate of Beauveria bassiana was detected, the $10 \mu \mathrm{L}$ sample was first dripped to the blood cell counting board, the spore concentration of the sample was observed and calculated under microscope, the dilution multiple was calculated with the target concentration of $1.0 \times 10^{5} \mathrm{CFU} / \mathrm{mL}$, the aseptic water was added according to the calculated multiple, and the $10 \mu \mathrm{L}$ of diluted drug solution was detected by blood cell counter. After the spore concentration reached $1.0 \times 10^{5}$, the liquid nutrition $(2 \%$ malt leaching powder aqueous solution) was added proportionately. The diluted liquid was dripped on the hydrophobic cover slide, and the cover slide was put into a disposable petri dish and sealed. It was then taken out after being cultured in an incubator at $24^{\circ} \mathrm{C}$ for $8 \mathrm{~h}$, and observed under microscope. The number of germinating spores and the activity retention rate were calculated.

\subsection{Evaluation method}

\subsubsection{Evaluation of droplet distribution uniformity}

In order to characterize the uniformity of droplet distribution, the relative width $S$ of droplet spectrum is usually expressed (such as Equation (1) $)^{[30]}$. The laser particle size analyzer recorded the collected data. Using $\mathrm{D}_{\mathrm{V} 10}, \mathrm{D}_{\mathrm{V} 50}$, and $\mathrm{D}_{\mathrm{V} 90}$, the relative width $S$ of the droplet spectrum of the nozzle can be calculated. The closer the $S$ is to 1 , the closer the droplet size distribution is to the normal distribution, that is, the more uniform the droplet distribution is.

$$
S=\frac{D_{V 90}-D_{V 10}}{D_{V 50}}
$$

\subsubsection{Activity retention rate of Bacillus thuringiensis}

In the experiment, the number of single colonies that were germinated was observed after culturing the three gradients of $10^{-1}$, $10^{-2}$ and $10^{-3}$ gradients. The number of single colonies germinated in a single petri dish was $40-100$ and three gradients were selected, where the most suitable gradient of them selected in the dilution gradient was used to calculate the number of single colonies. Through the experiment, it was found that the colony density was best when the dilution gradient was $10^{-2}$, and the number of single colonies in the sample was calculated. The number of single colonies germinated in three replications of each sample was $a_{1}, a_{2}$, and $\mathrm{a}_{3}$, as well as the germination of the control group. The number of single colonies is $\mathrm{CK}_{1}, \mathrm{CK}_{2}$, and $\mathrm{CK}_{3}$.

The activity retention rate of Bacillus thuringiensis samples was as follows:

$$
f_{1}=\frac{a_{1}+a_{2}+a_{3}}{C K_{1}+C K_{2}+C K_{3}}
$$

\subsubsection{Activity retention rate of Beauveria bassiana}

In the experiment of the activity retention rate of Beauveria bassiana, the droplets on the hydrophobic cover slide were observed under $10 \times 10$ times microscope, and the visual field (where the total number of spores were approximately 120 in the five fields of vision) was picked up at about five positions in the upper and lower parts of the droplets. The spore germination was recorded as spore germination with the length of bud tube exceeding the diameter of spores, and the number of spores germinated in the five fields was $b_{1}, b_{2}, b_{3}, b_{4}$, and $b_{5}$, whereas the total number of spores in the five fields of vision were $B_{1}, B_{2}, B_{3}$, $\mathrm{B}_{4}$, and $\mathrm{B}_{5}$.

The activity retention rate of Beauveria bassiana samples was as follows:

$$
f_{2}=\frac{b_{1}+b_{2}+b_{3}+b_{4}+b_{5}}{B_{1}+B_{2}+B_{3}+B_{4}+B_{5}}
$$

\section{Results and analysis}

\subsection{Speed calibration of blade rotary cage nozzle}

Considering the performance of the rotary cage nozzle and the safety of the test, the rotary speed of the nozzle exceeding 11000 $\mathrm{r} /$ min would not be recorded. The values of speed measurement are shown in Table 3.The data in table.3 are the condition parameters corresponding to the experimental speed close to the target speed $(3000 \mathrm{r} / \mathrm{min}, 5000 \mathrm{r} / \mathrm{min}$ and $7000 \mathrm{r} / \mathrm{min})$, and the column of "experimental speed/target speed" in the table are used to characterize the similarity between experimental speed and target Speed. The condition parameters in the particle size 
distribution test and biological pesticide activity test of the rotary cage nozzle are the same as Table 3 .

Table 3 Test condition parameters at different rotary speeds

\begin{tabular}{cccccc}
\hline Nozzle & $\begin{array}{c}\text { Target } \\
\text { speed } \\
/ \mathrm{r} \cdot \mathrm{min}^{-1}\end{array}$ & $\begin{array}{c}\text { Experimental speed/ } \\
\text { Target speed } \\
/ \%\end{array}$ & $\begin{array}{c}\text { Blade } \\
\text { length } \\
/ \mathrm{mm}\end{array}$ & $\begin{array}{c}\text { Blade } \\
\text { angle } \\
/\left(^{\circ}\right)\end{array}$ & $\begin{array}{c}\text { Wind } \\
\text { speed } \\
/ \mathrm{m}^{-1} \cdot \mathbf{s}^{-1}\end{array}$ \\
\hline \multirow{3}{*}{ CYD-1 } & 3000 & 97.1 & 94 & 45 & 25.5 \\
& 5000 & 102.3 & 68 & 45 & 33.8 \\
& 7000 & 98.4 & 68 & 35 & 33.8 \\
\hline \multirow{3}{*}{ CYD-2 } & 3000 & 103.7 & 94 & 45 & 25.5 \\
& 5000 & 102.0 & 68 & 35 & 33.8 \\
& 7000 & 99.3 & 94 & 35 & 33.8 \\
\hline \multirow{3}{*}{ CYD-3 } & 3000 & 95.7 & 94 & 35 & 25.5 \\
& 5000 & 107.3 & 68 & 25 & 33.8 \\
& 7000 & 96.2 & 68 & 35 & 42.6 \\
\hline
\end{tabular}

\subsection{Analysis of particle size distribution of droplets}

Table 4 presents the uniformity of droplet size distribution of different nozzles at different flow rate and rotary speeds of Bacillus thuringiensis, Beauveria bassiana, and water. Considering the interactivity of the three influencing factors, 27 experiments were performed for each medium. As can be observed from an analysis of the data in Table 4, the average relative width $S$ of the droplets are close to 1 under the three medium conditions, indicating that the rotary cage nozzle has good atomization effect on the three media, and the droplet size distribution is uniform. In terms of the average particle size of the droplets, the average droplet sizes of water, Bacillus thuringiensis, and Beauveria bassiana were $198.08 \mu \mathrm{m}, 238.11 \mu \mathrm{m}, 214.05 \mu \mathrm{m}$, which can be seen by comparison the average droplet size of the biological pesticide is significantly larger than the average droplet size of the water droplets. Under the same conditions, the average particle size of bacteria was larger than that of fungi, and under the same parameters, with the increase of rotary speed or nozzle diameter, the average particle size of droplets visibly decreased. This is attributable to the fact that the increasing the rotary speed and diameter will lead to the centrifugal force in the liquid, making the impact force and the shear force of the airflow becomes larger when the liquid reaches the net cage of the rotary cage nozzle, causing the particle size of the droplet to be smaller. The biological pesticide droplets of size less than $150 \mu \mathrm{m}$ are volatile and poorly resistant to drift. Therefore, it is recommended that the average volume of biological pesticide sprayed in aviation operations should not be less than $150 \mu \mathrm{m}$. Through the analysis of the experimental data, it can be seen that the droplet size generated when the rotary speed of the rotary nozzle exceeds $7000 \mathrm{r} / \mathrm{min}$ will be too small, which does not meet the operation requirements. The diameter of the rotary cage nozzle selected should not be too large. The droplet size of the $105 \mathrm{~mm}$ nozzle selected in this article is close to the critical value, and it is not appropriate to choose a nozzle with a larger diameter. During the spraying operation, because of the influence of the external environment, the spray pressure will be less than the $0.25 \mathrm{MPa}$ by the test set, and the droplet size will slightly increase.

Table 4 Droplet distribution parameters

\begin{tabular}{|c|c|c|c|c|c|c|c|c|}
\hline \multirow{2}{*}{ Factor } & \multirow{2}{*}{ Value } & \multirow{2}{*}{ Test times } & \multicolumn{3}{|c|}{ Droplet size distribution relative to broadband $S$} & \multicolumn{3}{|c|}{ Medium diameter of droplets size } \\
\hline & & & Water & Bacillus thuringiensis & Beauveria bassiana & Water & Bacillus thuringiensis & Beauveria bassiana \\
\hline \multirow{3}{*}{$\begin{array}{l}\text { Nozzle } \\
\text { diameter/ } \\
\text { mm }\end{array}$} & 105 & 27 & 1.352 & 0.899 & 1.579 & 163.03 & 190.9 & 181.22 \\
\hline & 85 & 27 & 1.404 & 1.07 & 1.806 & 197.95 & 247.5 & 224.75 \\
\hline & 65 & 27 & 1.478 & 1.108 & 2.086 & 233.26 & 275.92 & 236.19 \\
\hline \multirow{3}{*}{$\begin{array}{l}\text { Flow rate/ } \\
\mathrm{L} \cdot \mathrm{min}^{-1}\end{array}$} & 4.4 & 27 & 1.478 & 1.048 & 2.002 & 196.21 & 236.78 & 213.64 \\
\hline & 10.5 & 27 & 1.403 & 0.958 & 2.086 & 197.76 & 238.13 & 213.38 \\
\hline & 11.1 & 27 & 1.42 & 0.899 & 1.991 & 200.28 & 239.41 & 215.15 \\
\hline \multirow{3}{*}{$\begin{array}{l}\text { Rotary } \\
\text { speed/ } \\
\mathrm{r} \cdot \mathrm{min}^{-1}\end{array}$} & 3000 & 27 & 1.187 & 0.899 & 1.744 & 276.62 & 350.25 & 291.11 \\
\hline & 5000 & 27 & 1.403 & 1.22 & 1.801 & 179.12 & 213.43 & 196.96 \\
\hline & 7000 & 27 & 1.478 & 1.231 & 2.086 & 138.51 & 150.63 & 154.1 \\
\hline
\end{tabular}

Table 5 Analysis of variance of multi-factor influence

\begin{tabular}{cccccc}
\hline Source & $\begin{array}{c}\text { Correction } \\
\text { model }\end{array}$ & Intercept & $\begin{array}{c}\text { Nozzle } \\
\text { diameter }\end{array}$ & $\begin{array}{c}\text { Rotary } \\
\text { speed }\end{array}$ & Flow rate \\
\hline Significance & 0.000 & 0.000 & 0.000 & 0.000 & 0.926 \\
partial Eta Squared & 0.700 & 0.995 & 0.293 & 0.657 & 0.003 \\
\hline
\end{tabular}

In order to explore the influence of the above variables on the uniformity of droplet size distribution, the multivariate ANOVA based on SPSS software was used to test the inter-subject effects of the relative width $S$ of the droplet spectrum. From the analysis results in Table 5, it can be determined that the significance value of the rotary speed and the nozzle diameter is 0 , which is less than 0.05 , denoting that the rotary speed and nozzle diameter have a significant influence on the droplet size. The significance value of the flow rate is 0.926 , which is significantly greater than 0.05 , indicating that the flow rate has no significant effect on the uniformity of droplet size distribution. Comparing the estimated metrics of efficient estimations to partial Eta squared, the partial Eta squared of the rotary speed is the largest, the partial Eta squared of the nozzle diameter is the second largest, and both pass the significance test. The partial Eta squared of the flow rate is 0.003 , and the significance test was not passed. Therefore, it can be concluded that the influence of the variables set in the experiment on the uniformity of the droplet size distribution is rotary speed $>$ nozzle diameter $>$ flow rate, while the flow rate has little effect on the uniformity of droplet size distribution.

In summary, it can be determined that the degree of influence on the uniformity of particle size distribution of biological pesticide droplets is: rotary speed $>$ nozzle diameter $>$ flow rate.

\subsection{Analysis of the effect of activity retention rate}

A sample of Bacillus thuringiensis was cultured for $8 \mathrm{~h}$, as shown in Figure 4. Figure 4 presents three biological replications of the same sample, and the activity retention rate of Beauveria bassiana was calculated by counting the number of single colonies $a_{i}(i=1,2,3)$ on the culture medium and the number of single colonies $\left(\mathrm{CK}_{1}, \mathrm{CK}_{2}\right.$, and $\left.\mathrm{CK}_{3}\right)$ in the control group. One of the Beauveria bassiana samples cultured for $16 \mathrm{~h}$ are shown in Figure 5. Figure 5 depicts the electron microscopic images of five random visual fields observed under electron microscope after the sample was cultured. The average activity retention rate of the 
sample was calculated by counting the number of germinated spores $b_{i}(i=1,2,3,4,5)$ and the total spore number $B_{i}(i=1,2,3$, $4,5)$. The average activity retention rate of Bacillus thuringiensis
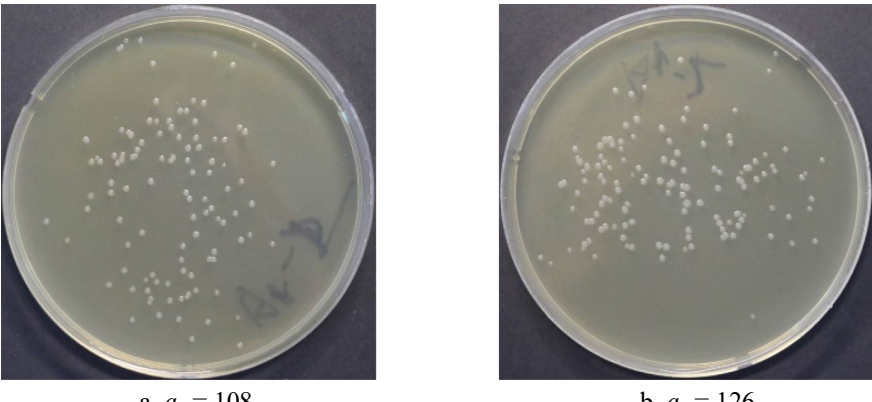

b. $a_{2}=126$ samples was $91.7 \%\left(\mathrm{CK}_{1}=120, \mathrm{CK}_{2}=131, \mathrm{CK}_{3}=124\right) . \quad$ The average activity retention rate of Beauveria bassiana samples was $89.9 \%$.

Figure 4 Average germination rate of the Bacillus thuringiensis sample

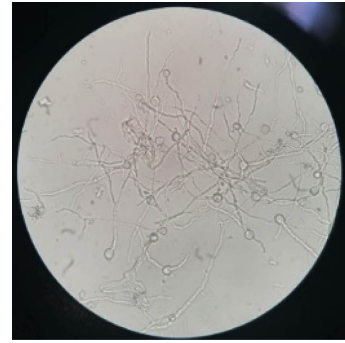

a. $b_{1}=118, B_{1}=134$

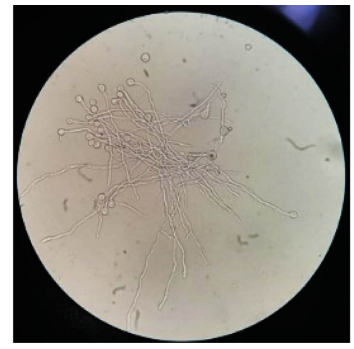

b. $b_{2}=124, B_{2}=139$

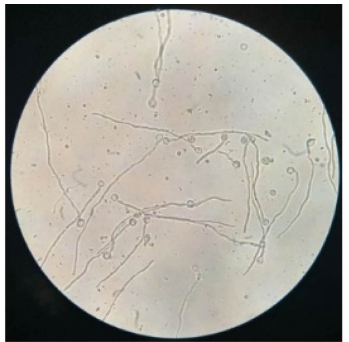

c. $b_{3}=125, B_{3}=137$

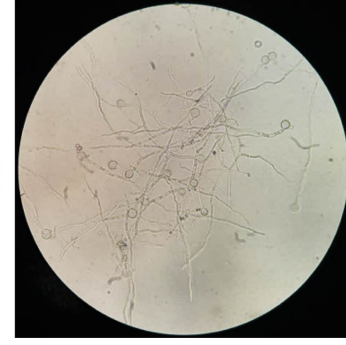

d. $b_{4}=105, B_{4}=119$

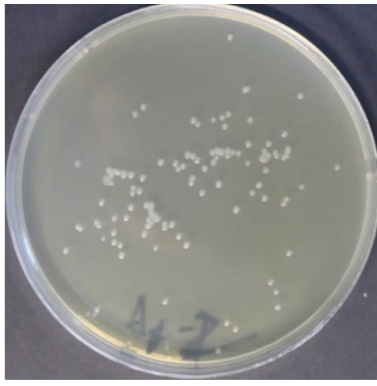

c. $a_{3}=110$

Figure 5 Average germination rate of the Beauveria bassiana sample

The average activity retention rate is shown in Table 6 . The data in Table 6 indicates that the average activity retention rate of Bacillus thuringiensis was $88.83 \%$, the lowest was $83.52 \%$, and the highest was $92.82 \%$; and the average germination rate of Beauveria bassiana was $89.80 \%$, the lowest was $84.59 \%$, and the highest was $97.79 \%$. The germination rate of Beauveria bassiana was slightly higher than that of Bacillus thuringiensis as a whole.

Table 6 Average germination rate

\begin{tabular}{|c|c|c|c|c|c|c|}
\hline \multirow{3}{*}{ Factor } & \multirow{3}{*}{ Value } & \multirow{3}{*}{$\begin{array}{l}\text { Test } \\
\text { times }\end{array}$} & \multicolumn{4}{|c|}{ Biological pesticide activity retention rate $/ \%$} \\
\hline & & & \multicolumn{2}{|c|}{ Bacillus thuringiensis } & \multicolumn{2}{|c|}{ Beauveria bassiana } \\
\hline & & & Max & Min & Max & Min \\
\hline \multirow{3}{*}{$\begin{array}{l}\text { Nozzle } \\
\text { diameter/ } \\
\text { mm }\end{array}$} & 105 & 27 & 92.82 & 86.34 & 97.79 & 87.61 \\
\hline & 85 & 27 & 91.7 & 85.8 & 93.18 & 85.92 \\
\hline & 65 & 27 & 90.28 & 86.23 & 91.95 & 84.59 \\
\hline \multirow{3}{*}{$\begin{array}{l}\text { Flow rate/ } \\
\mathrm{L} \cdot \mathrm{min}^{-1}\end{array}$} & 4.4 & 27 & 92.82 & 83.52 & 92.55 & 87.04 \\
\hline & 10.5 & 27 & 91.67 & 86.52 & 92.4 & 84.67 \\
\hline & 11.1 & 27 & 91.7 & 85.8 & 97.79 & 84.59 \\
\hline \multirow{3}{*}{$\begin{array}{l}\text { Rotary } \\
\text { speed/ } \\
\mathrm{r} \cdot \mathrm{min}^{-1}\end{array}$} & 3000 & 27 & 92.82 & 86.58 & 93.18 & 90.29 \\
\hline & 5000 & 27 & 91.2 & 86.23 & 97.79 & 86.27 \\
\hline & 7000 & 27 & 89.28 & 83.52 & 91.23 & 84.59 \\
\hline
\end{tabular}

In addition, the activity retention rate of biological pesticides noticeably decreased with the decrease of nozzle diameter or the increase of rotary speed. This is due to the decrease of nozzle diameter or the increase of rotary speed leading to the instantaneous pressure and airflow cutting force of biological pesticides in vivo, resulting in the destruction of bacterial structure and the decrease of germination rate.

In order to explore the influence of several variables set in this paper on the activity retention rate of Bacillus thuringiensis, the data were tested for inter-subject effects. The results are presented in Table 7. In the main effect test, the significance level of the flow rate was 0.640 , the significance level of the nozzle diameter was 0.257 , and none of them passed the significance test.
Through the significance test, the significance level of the rotary speed was 0.02 , which is less than 0.05 . Only the rotary speed was significantly affected by the activity retention rate of Bacillus thuringiensis. Compared with partial Eta squared, it can be observed that the order of influence of several factors on the activity retention rate of Bacillus thuringiensis is as follows: rotary speed $>$ nozzle diameter $>$ flow rate. In the main effect test of the germination rate of Beauveria bassiana, the partial Eta squared of the nozzle diameter was 0.063 , which was greater than 0.05 ; the partial Eta squared of the flow rate was 0.808 , which was greater than 0.05 ; and none of them passed the significance test. The partial Eta squared of the rotary speed was 0.01 , which was less than 0.05 , reaching an extremely significant level.

Table 7 Analysis of variance of multi-factor influence

\begin{tabular}{|c|c|c|c|c|c|c|}
\hline Source & medium & $\begin{array}{c}\text { Correction } \\
\text { model }\end{array}$ & Intercept & $\begin{array}{l}\text { Nozzle } \\
\text { diameter }\end{array}$ & $\begin{array}{l}\text { Rotary } \\
\text { speed }\end{array}$ & $\begin{array}{l}\text { Flow } \\
\text { rate }\end{array}$ \\
\hline \multirow{2}{*}{ Significance } & $\begin{array}{c}\text { Bacillus } \\
\text { thuringiensis }\end{array}$ & 0.014 & 0.000 & 0.257 & 0.002 & 0.640 \\
\hline & $\begin{array}{c}\text { Beauveria } \\
\text { bassiana }\end{array}$ & 0.004 & 0.000 & 0.063 & 0.001 & 0.808 \\
\hline \multirow{2}{*}{$\begin{array}{c}\text { Partial eta } \\
\text { squared }\end{array}$} & $\begin{array}{c}\text { Bacillus } \\
\text { thuringiensis }\end{array}$ & 0.520 & 1.000 & 0.127 & 0.472 & 0.044 \\
\hline & $\begin{array}{c}\text { Beauveria } \\
\text { bassiana }\end{array}$ & 0.589 & 1.000 & 0.241 & 0.522 & 0.021 \\
\hline
\end{tabular}

By comparing the activity retention rate of Bacillus thuringiensis and Beauveria bassiana, it can be understood that the activity retention rate of Beauveria bassiana is higher than that of Bacillus thuringiensis under the same condition. This is attributable to the fact that although the bacteria have the same cell wall structure as fungi, the constituent material of the cell wall is different. The peptidoglycan cell wall of bacteria is more vulnerable to damage, leading to the difference of activity retention rate between the two biological pesticides under the same conditions. From the above comprehensive analysis, it can be determined that the rotary speed has a significant effect on the 
activity retention rate of biological pesticides and is negatively correlated.

\section{Conclusions}

From the perspective of uniformity distribution of droplet size and biological pesticide activity retention rate, the droplet particle size distribution and activity retention rate tests were carried out by spraying the different kinds of biological pesticides at different flows and rotary speeds by using rotary cage nozzles with different structure sizes. The results are as follows:

1) The average relative width $S$ of the droplets spectrum of the rotary cage nozzle was close to 1 , and the droplets were evenly distributed. The important influence factors on the particle size distribution of biological pesticide droplets were as follows in the descending order: rotary speed, nozzle diameter, medium, and flow rate. The rotary speed, nozzle diameter, and medium had a significant influence on the droplet size distribution, whereas the flow rate had no significant effect.

2) The flow rate and nozzle diameter had no significant effect on the activity retention rate of bacterial and fungal biological pesticides, but the rotary speed had a significant effect on the activity retention rate of bacterial and fungal biological pesticides, and it was negatively correlated: the higher the rotary speed, the lower the activity retention rate. From the angle of improving the activity retention rate of biological pesticides, it is suggested that the recommended working speed should be selected between $3000-5000 \mathrm{r} / \mathrm{min}$.

3) Under the same conditions, the activity of fungal bio-pesticides is higher than that of bacterial bio-pesticides, which is mainly caused due to differences in cell structure. From the perspective of improving the control effect of bio-pesticides, fungal biological pesticides are preferred under the same working conditions.

\section{Acknowledgements}

The research was funded by the National Key Research and Development Program of the 13th Five-Year Plan (Project No. 2018YFC1200400, and Project No. 2018YFD0600202).

\section{[References]}

[1] Yang Z Q, Wang X Y, W, Zhang Y N, Zhang Y L. Research progress on comprehensive control of major forest diseases and insect pests in China based on biological control. Chinese Journal of Biological Control, 2018; 34(2): 163-183. (in Chinese)

[2] Zhang Y L, Lan Y B, Fritz B K. Development history of American aviation electrostatic spray system and its application status in China. Transactions of the CSAE, 2016; 32(10): 1-7. (in Chinese)

[3] Teske M E, Bowers J F, Rafferty J E, Barry J W. FSCBG: An aerial spray dispersion model for predicting the fate of released material behind aircraft. Environmental Toxicology \& Chemistry, 2010; 12(3): 453-464

[4] Tang Q, Chen L P, Zhang R R, Zhang B, Yi T C, Xu M, et al. Atomization characteristics of standard fan-shaped nozzles and air-induced nozzles under high-speed airflow conditions. Transactions of the CSAE, 2016; 32(22): 121-128. (in Chinese)

[5] Changchun X. Review of the "13th five-year" national key R\&D program for pesticide reduction and efficiency projects. Plant Protection, 2018; 44(5): 96-99, 180. (in Chinese)

[6] Gupta S, Dikshit A K. Biopesticides: An ecofriendly approach for pest control. Journal of Biopesticides, 2010; 3(1): 186-188.

[7] Glare T R, Moran-Diezr L. Biopesticides: methods and protocols methods in molecular biology. New Delhi: Spinger India, 2016; pp.211-221.

[8] Mehrotro S, Kumar S, Zahid M, Garg M. Principles and applications of environmental biotechnology for a sustainable future. Springer Link, 2017; pp.273-292.
[9] Xiao L P, Liu M H, Zhu H P, Cai J P, Lin J L, Ou M X, et al. Spray droplet size characteristics of different biological pesticides with different hydraulic nozzles. Transactions of the CSAM, 2018; 49(2): 100-106. (in Chinese)

[10] Brusselman E, Beck B, Temmerman F, Pollet S, Steurbaut W, Moens M, et al. Distribution of entomopathogenic nematodes in a biopesticide spray. Transactions of the ASABE, 2011; 54(6): 1981-1989.

[11] Patel M K, Praveen B, Sahoob H K, Patel B, Kumarb A, Singh M. An advance air-induced air-assisted electrostatic nozzle with enhanced performance. Computers and Electronics in Agriculture, 2017; 135: 280-288.

[12] Doruchowski G, Swiechowski W, Trzcinski P, SasPaszt L, Hołownicki R. Effect of spray application parameters on viability of rhizobacteria used as bio-pesticides in organic fruit production. 13th Workshop on Spray Application in Fruit Growing, 2015; 448: 60-61.

[13] Hidalgo E, Bateman R, Krauss U, Hoopen M, Martínez A. A field investigation into delivery systems for agents to control moniliophthoraroreri. European Journal of Plant Pathology, 2003; 109(9): 953-961.

[14] Gouli V, Kassa A, Skinner M, Parker B L. Fungal conidia distribution on chrysanthemum: varying spray parameters. Archives of Phytopathdogy and Plant Protection, 2011; 44(6): 567-574.

[15] Fife J P, Derksen R C, Ozkan H E, Grewal P S. Effects of pressure differentials on the viability and infectivity of entomopathogenic nematodes. Biological Control, 2003; 27(1): 65-72.

[16] Molina-Miras A, Sánchez-Mirón A, García-Camacho F, Molina-Grima E. CFD-aided optimization of a laboratory-scale centrifugation for a shear-sensitive insect cell line. Food \& Bioproducts Processing, 2018; 107: 113-120.

[17] Jane P, Fife, Richard C Derksen, H Erdal Ozkan,Parwinder S Grewal, Jeffrey J Chalmers, Charles R Krause. Evaluation of a contraction flow field on hydrodynamic damage to entomopathogenic nematodes-A biological pest control agent. Biotechnology \& Bioengineering, 2004; 86(1): 96-107.

[18] Fife J P, Ozkan H E, Derksen R C, Grewal P S. Using computational Fluid dynamics to predict damage of a biological pesticide during passage through a hydraulic nozzle. Biosystems Engineering, 2006; 94(3): 387-396.

[19] Fife J, Ozkan E, Derksen R, Grewal P S. Viability of a biological pest control agent through hydraulic nozzles. Transactions of the ASAE, 2005; 48(1): 45-54.

[20] Li J H, Zheng J Q, Yu G. Two-phase flow of spray-inoculated biological particles and its effect on strain activity. Transactions of the CSAE, 2014; 30(1): 47-54. (in Chinese)

[21] Zhai E Y, Zheng J Q, Zhou H P, Ru Y, Li J H. Effect of fan-shaped mist nozzle wear on microbial pesticide application performance. Transactions of Forestry Engineering, 2018; 3(1): 109-116. (in Chinese)

[22] Zhang H C, Gary Dorr, Zheng J Q, Zhou H P. Wind tunnel experiment and regression model for spray drift. Transactions of the CSAE, 2015; 31(3): 94-100. (in Chinese)

[23] Song W, Zhou H P, Zhang H C, Yu J, Dai Z H. Performance Analysis of Rotary Cage Biological Pesticide Atomizing Nozzle. Journal of Nanjing Forestry University: Natural Science Edition, 2012; 36(5): 133-136. (in Chinese)

[24] Zhang H C, Gary Dorr, Zheng J Q, Zhou H P. Performance of centrifugal atomizing nozzle for wind-driven rotary bio-pesticide. Journal of Zhejiang Agriculture and Forestry University, 2018; 34(2): 361-366. (in Chinese)

[25] Zhang H C, Zhu Z Y, Zheng J Q, Zhou H P, Tang J G. Biopesticide spraying system for forestry pest control. Forestry Science, 2018; 54(10): 119-127.

[26] Gan-Mor S, Matthews G A. Recent Developments in Sprayers for Application of Biopesticides - an Overview. Biosystems Engineering, 2003; 84(2): 119-125.

[27] Bagherpour A, Mcleod I M, Holloway A G L. Droplet sizing and velocimetry in the wake of rotary-cage atomizers. Transactions of the ASABE, 2012; 55(3): 759-772.

[28] Patel M K, Ghanshyam C. Fundamentals of electrostatic spraying: Basic concepts and engineering practices. Handbook of Research on Uncovering New Methods for Ecosystem Management through Bioremediation, Shivom S and Kajal S, Eds., Hershey, PA, USA: IGI Global, 2015; pp. 461-490.

[29] Hooper G H S, Spurgin P A. Droplet size spectra produced by the atomization of a ULV formulation of fenitrothion with a Micronair AU5000 rotary atomizer. Crop Protection, 1995; 14(1): 27-30.

[30] Ru Y, Zhu C Y, Bao R, Li Z F, Ding T. Droplet size distribution of aerial nozzle for plant protection in wind tunnel and flight conditions. Transactions of the CSAE, 2016; 32 (20): 94-98. (in Chinese) 